\title{
ORIGINAL ARTICLE Systemic serum amyloid A as a biomarker for exposure to zinc and/or copper-containing metal fumes
}

\author{
R Baumann ${ }^{1}$, M Gube ${ }^{1}$, A Markert ${ }^{1}$, S Davatgarbenam ${ }^{1}$, V Kossack ${ }^{1}$, B Gerhards ${ }^{2}$, T Kraus $^{1}$ and P Brand $^{1}$
}

\begin{abstract}
Zinc- and copper-containing welding fumes increase systemic C-reactive protein (CRP). The aim of this study was to investigate the performance of the biomarkers serum amyloid A (SAA) and soluble vascular cell adhesion molecule-1 (VCAM-1) in this regard. Fifteen male subjects were exposed under controlled conditions to welding fumes containing either zinc, or copper, or copper and zinc for $6 \mathrm{~h}$. Plasma samples were collected before, 6 and $24 \mathrm{~h}$ after start of exposure and biomarkers therein were measured by electrochemiluminescent assay. For each exposure, systemic concentrations of systemic SAA, but not VCAM-1, increased significantly at $24 \mathrm{~h}$ after exposure start compared with baseline ("copper only": $P=0.0005$, "zinc only": $P=0.027$, "copper and zinc": $P=0.001)$. SAA showed a wider range of concentrations than did CRP and its levels increased up to 19-fold after welding fume exposure. The recognition of copper as a potential harmful component in welding fumes, also independent from zinc, deserves further consideration. SAA might represent a new sensitive biomarker for potential subclinical sterile inflammation after inhalation of copper- and/or zinc-containing welding fumes. As elevations of CRP and SAA protein have both been linked to a higher risk for cardiovascular disease, these findings might particularly be important for long-term welders.
\end{abstract}

Journal of Exposure Science and Environmental Epidemiology (2018) 28, 84-91; doi:10.1038/jes.2016.86; published online 8 February 2017

Keywords: Inflammation; Risk for cardiovascular disease; SAA; Welding; Zinc; Copper

\section{INTRODUCTION}

A large number of workers are exposed to welding fumes containing various types of gases and metal particles in occupational settings. Depending on the constitution of the welding fumes and the respective exposure conditions, epidemiological studies have shown that welding fume exposure is associated with the risk of health impairment through respiratory illness, inflammation and cardiovascular disease. ${ }^{1-4}$

Zinc and copper play an increasing role in modern joining technology, especially in the automotive industry, and hence exposures from workers become more frequent. In a recent study, a distinct increase of systemic C-reactive protein (CRP) has been shown after inhalation of welding fume from a metal inert gas brazing process of zinc-coated steel using a copper-containing welding wire at an average fume concentration of $2.5 \mathrm{mg} / \mathrm{m}^{3.5} \mathrm{~A}$ further study tested the effect of elevated systemic CRP levels after exposure with three different doses of this welding fume and found increases of CRP after exposure with 2.0 and $2.5 \mathrm{mg} / \mathrm{m}^{3}$ average fume concentration, but not at $1.4 \mathrm{mg} / \mathrm{m}^{3}$. Hence, it was concluded that the no-observed-effect level for systemic inflammation after such exposures was $1.4 \mathrm{mg} / \mathrm{m}^{3}$ and the lowest observed effect level was $2.0 \mathrm{mg} / \mathrm{m}^{3}$. This corresponds to zinc concentrations of $0.84 \mathrm{mg} / \mathrm{m}^{3}$ and $1.2 \mathrm{mg} / \mathrm{m}^{3}$, respectively, and copper concentrations of $0.24 \mathrm{mg} / \mathrm{m}^{3}$ and $0.34 \mathrm{mg} / \mathrm{m}^{3}$, respectively. ${ }^{6}$ A subsequent third study showed that the observed effects were due to the zinc as well as copper present in the welding fume, as the welding fumes which contained either zinc and no copper, or copper and no zinc, were also able to cause significant systemic CRP increases after a short-term inhalation. ${ }^{7}$
Even moderate elevations of systemic CRP indicate an increased risk for cardiovascular diseases. ${ }^{8}$ As short-term inhalations of zincand/or copper-containing welding fumes have been shown to elicit significant CRP elevations, ${ }^{5-7}$ the question arises whether workers exposed to these metal fumes have an increased risk to develop cardiovascular diseases, as epidemiological studies suggest. $^{3}$

In order to investigate these and further biological effects and potential health risks after short-term inhalation of zinc- and/or copper-containing welding fumes, our aim in the present study was to investigate the performance of two other systemic biomarkers, serum amyloid A (SAA) and vascular cell adhesion molecule-1 (VCAM-1), after exposure to the three previously described "zinc only", or "copper only", or "copper and zinc" welding scenarios." The mass concentrations of the copper and zinc particles in the metal fumes equalled those used before. ${ }^{5}$

Like CRP, SAA is a positive acute-phase reactant and a sensitive marker of an acute inflammation. Its levels increase within hours after inflammatory stimuli, in part to levels greater than those of CRP. SAA is synthesized not only in the liver, but also extrahepatically, for example, by macrophages and endothelial cells. ${ }^{9}$ While CRP promotes efficient phagocytosis of dying cells by macrophages, SAA may enhance the export of free cholesterol/ phospholipid by macrophages for reuse. ${ }^{10}$ Further suggested functions of SAA comprise chemotaxis for monocytes and neutrophils, the promotion of pro-inflammatory cytokine expression, and the prolongation of the lifespan of neutrophils through an antiapoptotic effect. ${ }^{11,12}$ Elevated SAA levels are implicated in several chronic inflammatory diseases, such as amyloidosis,

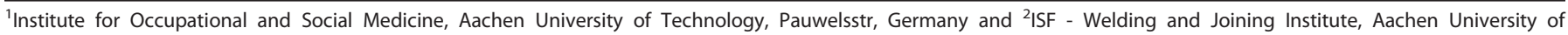

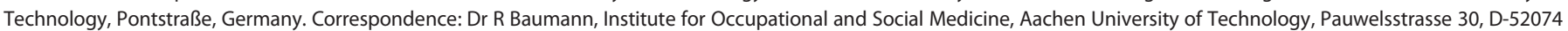
Aachen, Germany.

Tel.: +4924180 80473. Fax: +492418082587.

E-mail: RBaumann@ukaachen.de

Received 25 April 2016; accepted 6 December 2016; published online 8 February 2017 
atherosclerosis, rheumatoid arthritis and chronic obstructive pulmonary disease (COPD), ${ }^{12,13}$ suggesting that SAA may have an active role in these diseases. Similar to CRP, SAA is a biomarker for the prediction of cardiovascular diseases. ${ }^{14}$ Moreover, chronically and also briefly elevated SAA levels were recently shown to increase atherosclerosis in a murine model. ${ }^{15,16}$

The glycoprotein VCAM-1 (CD106) is a member of the immunoglobulin superfamily expressed mainly by activated endothelial cells, which mediates the adhesion of monocytes, eosinophils and lymphocytes. VCAM-1 expression is induced by IL-1 $\beta$, IL-4, TNF- $\alpha$ and IFN- $\gamma$. Therefore, VCAM- 1 is a marker of endothelial inflammation. It is not expressed under baseline conditions but is rapidly induced by pro-atherosclerotic conditions. ${ }^{17}$ Soluble VCAM-1 is shed from endothelial cell surfaces and is readily detectable in serum. ${ }^{18}$

The investigation of the performance of these two further pro-atherosclerotic biomarkers after short-term exposure with copper- and/or zinc-containing welding fumes is needed to further elaborate on potential harmful effects of these metal fumes particularly on long-term cardiovascular health.

\section{METHODS}

\section{Subjects}

The study group consisted of 15 non-smoking healthy male volunteers (mean age 26 years; mean weight $85.4 \mathrm{~kg}$; healthy lung function data) without any occupational metal fume exposure or history of atopy, asthma or any other lung or cardiac disease. The anthropometric and lung function data of the study population have been described previously. The study protocol was approved by the Ethics Committee of the Medical Faculty of the RWTH Aachen University and informed consent was obtained in writing from each subject prior to inclusion. For one subject, two exposure data sets had to be rejected due to nasal herpes virus infection and elevated CRP levels. Data sets from another two subjects were rejected due to a beforehand undetected ulcerated tooth root and flu infection and distinctively elevated serum CRP concentrations before start of exposure.

\section{Controlled Short-Term Exposure with Defined Welding Fumes}

Fifteen male subjects were exposed in a randomized threefold cross-over study to welding fumes containing at 1 day "zinc only" (target zinc concentration (tc): $1.5 \mathrm{mg} / \mathrm{m}^{3}$ ), at another day "copper only" (target copper concentration tc: $0.4 \mathrm{mg} / \mathrm{m}^{3}$ ) and on the third day both "zinc and copper" (zinc tc: $1.5 \mathrm{mg} / \mathrm{m}^{3}$; copper tc: $0.4 \mathrm{mg} / \mathrm{m}^{3}$ ). The duration of each exposure was $6 \mathrm{~h}$. The time between the different exposures was 1 week. On each exposure day, five subjects were present in the exposure room resulting in a total of three exposure days per week. The subjects entered the exposure laboratory within a time difference of $\sim 20$ min. For safety reasons, the lung function was measured before and after exposure using body plethysmography (data not shown). Once an hour, each subject cycled inside the exposure laboratory for $10 \mathrm{~min}$ on a bicycle ergometer at $80 \mathrm{~W}$ to simulate physical work. Blood samples were taken before, directly after end of exposure, and $24 \mathrm{~h}$ after exposure start. Exposure was performed in the "Aachen Workplace Simulation Laboratory", which consists of the emission room in which the welding fumes are generated and the exposure room in which the test subjects are exposed. Both units are connected by a ventilation system, which allows regulating the fume concentration in the exposure room. ${ }^{5,19}$ Welding was performed fully mechanized below a funnel-shaped fume hood, which was connected with the ventilation system of the exposure laboratory. Welding frequency was adjusted in order to achieve an average fume mass concentration of $2.5 \mathrm{mg} / \mathrm{m}^{3}$. The employed welding processes and materials, and the characterization of the fume concentration and composition, were described in detail before. ${ }^{7}$

\section{SAA and VCAM-1 Electrochemiluminescent Immunoassay}

SAA and VCAM-1 levels in plasma samples were analyzed using an electrochemiluminescent immunoassay (Catalog No. K15198D-1, with SAA and VCAM-1; Meso Scale Discovery (MSD), Gaithersburg, MD, USA). The matrix inhibitory effects of serum and plasma matrices on the detection of soluble cytokines using immunoassays has been shown to exist to a much lesser extent in the electro-chemiluminescence platform from MSD, when compared with either magnetic or polystyrene bead Luminex assays. ${ }^{20}$
The average spike recovery for SAA in EDTA plasma was 101\%, with a coefficient of variation (CV) of 9.3\%. The corresponding recovery range was between $75 \%$ and $125 \%$. The average spike recovery for VCAM-1 in EDTA plasma was $93 \%$, with a $\mathrm{CV}$ of $6.9 \%$. The corresponding recovery range was between $80 \%$ and $120 \%$. For every immunoassay, standards and samples were diluted in Diluent 101. After washing the plates three times with wash buffer, $25 \mu \mathrm{l}$ of standard or diluted plasma samples were added per well. Plates were incubated for $2 \mathrm{~h}$. All incubations of the immunoassay were done sealed on an orbital shaker (Titramax, Heidolph Instruments, Schwabach, Germany) at room temperature. After 3 washes, $25 \mu \mathrm{l}$ of detection antibody labeled with Sulfo-Tag (MSD) were added to each well and incubated for 1 additional hour protected from light. After further three washes, $150 \mu \mathrm{l}$ of $1 \times$ read buffer (MSD) was added per well and the plate was immediately read on the Meso Quick Plex SQ 120 (MSD). Raw data were analyzed using the Discovery Workbench 4.0 software (MSD). Standards and samples were measured in duplicates and CV values were $<20 \%$, and further in most cases $<12 \%$. The data are available upon request.

\section{Statistics}

Statistical analyses were performed using MedCalc software 15 (MedCalc Software, Oostende, Belgium). Graphs were generated with GraphPad Prism (Graph Pad, San Diego, CA, USA). The two differences for the two values (i) directly after the end of exposure ( $6 \mathrm{~h}$ after exposure start) and (ii) $24 \mathrm{~h}$ after exposure start were calculated in comparison to the baseline value before exposure $(0 \mathrm{~h})$. The hypothesis that the median of the differences is equal to zero was tested using the Wilcoxon signed rank sum test with an exact $P$-value (without the Normal distribution approximation). Comparisons between groups were performed using the non-parametric Kruskal-Wallis test with the difference of the biomarker concentration as dependent variable and the exposure scenario index as independent variable. Correlations were evaluated using the Spearman rank test. Receiver operating characteristic (ROC) curve analyses were performed and area under the ROC curves (AUCs) calculated. Generally, a two-tailed $P$-value of $P \leq 0.05$ was considered significant.

\section{RESULTS}

The individual time courses of systemic SAA separated for the three investigated controlled exposure scenarios "copper only", "zinc only" and "copper and zinc" are shown either as differences of the SAA concentrations compared with the base value (Figure 1a) or as absolute concentration values (Figure $1 \mathrm{~b}$ ). Whereas only minimal changes of SAA were measured at $6 \mathrm{~h}$ after start of exposure (directly after the end of the exposure), clear increases of SAA were detected at the $24 \mathrm{~h}$ time point (Figures $1 \mathrm{a}$ and b). Using the Wilcoxon signed rank sum test to test the hypothesis that the median of the differences of the SAA concentrations at the 6 and $24 \mathrm{~h}$ time point each compared with the baseline is equal to zero, we found significant changes at $24 \mathrm{~h}$ for all three exposure scenarios: "copper only": $P=0.0005$, "zinc only": $P=0.027$, "copper and zinc": $P=0.0010$ (Figure 1c). This indicates that copper as well as zinc are able to induce systemic inflammation. Although the Kruskal-Wallis test showed no significant difference of the differences of SAA $24 \mathrm{~h}$ after exposure versus before exposure among the three exposure scenarios (not shown), there seems to be a tendency to a lower effect for the exposure with "zinc alone".

The individual time courses of systemic VCAM-1/CD106 (separated for the three investigated controlled exposure scenarios) are also shown either as differences of the SAA concentrations compared with the base value (Figure 2a) or as absolute concentration values (Figure $2 \mathrm{~b}$ ). We observed only small changes of VCAM-1 at 6 and $24 \mathrm{~h}$ after start of exposure compared with baseline (Figures 2a and b). Using the Wilcoxon signed rank sum test to test the hypothesis that the median of the differences of the VCAM- 1 concentrations at the 6 and $24 \mathrm{~h}$ time point each compared with the baseline is equal to zero, we found no significant changes (Figure 2c). 

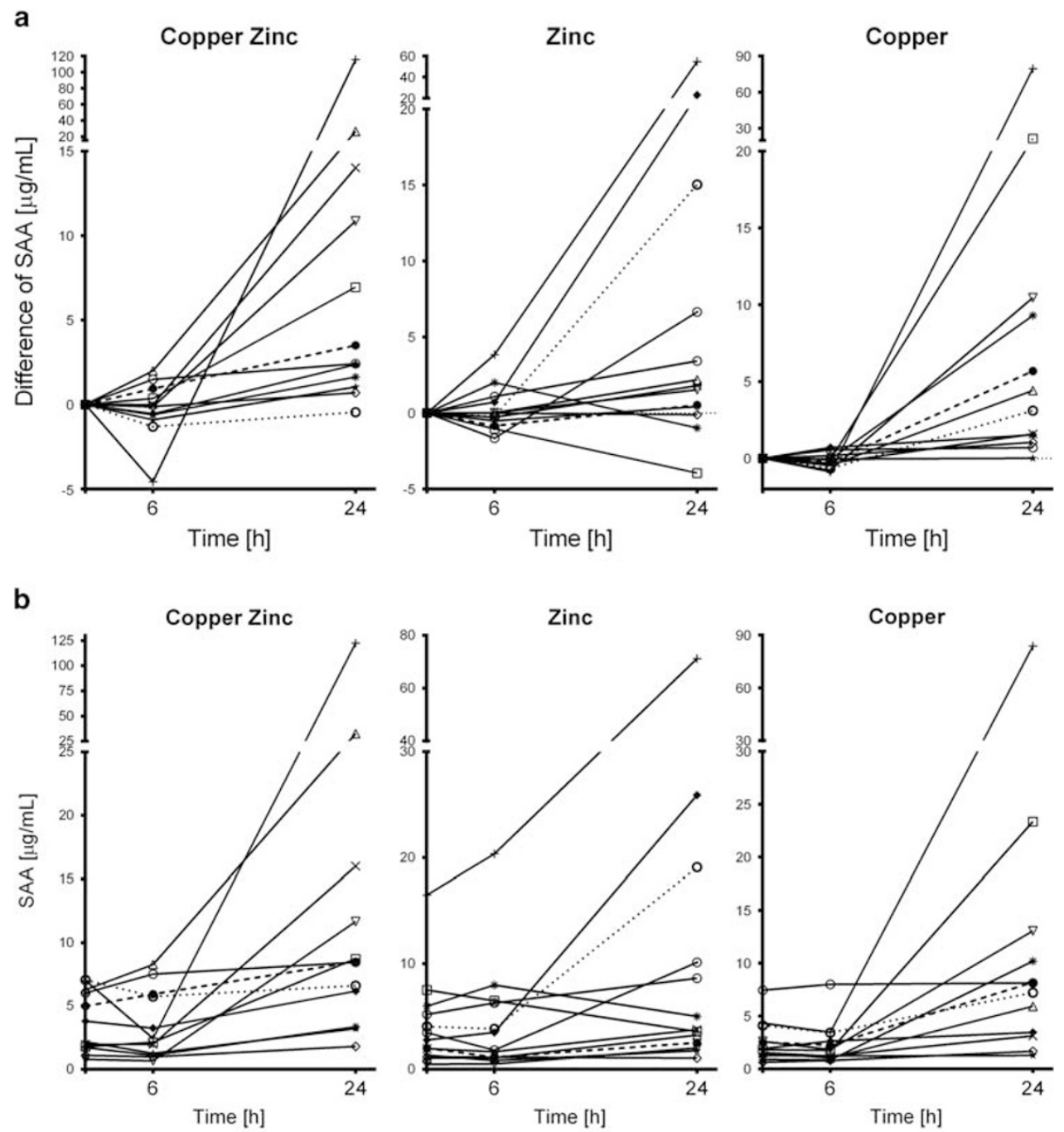

C

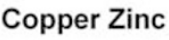

Zinc

Copper
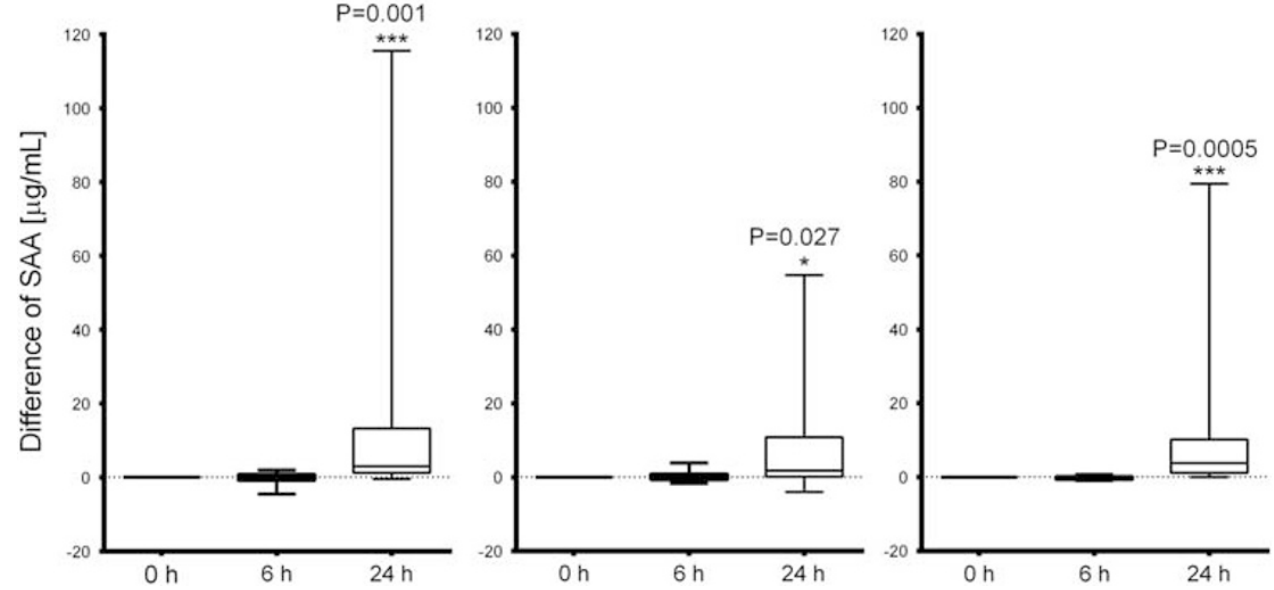

Figure 1. SAA concentrations in the blood for the three different exposure scenarios with welding fume containing copper and zinc together, zinc alone as well as copper alone. (a-c) represent alternative depictions of the results. (a) Time course of the difference of the SAA concentrations compared with the base value for each participant and exposure scenario. (b) Time course of the SAA concentrations for each participant and exposure scenario. (c) Box-and-Whisker Plot comparison of the differences of the SAA concentration compared with the base value at the time points. The hypothesis that the median of the difference of SAA at $24 \mathrm{~h}$ after exposure, or alternatively at $6 \mathrm{~h}$ after exposure, versus before exposure is equal to zero was tested using the Wilcoxon signed rank test. A $P$-value of $\leq 0.05$ was judged significant and levels of significance were indicated as follows: ${ }^{*} P=0.01-0.05,{ }^{* *} P=0.001-0.01,{ }^{* * *} P \leq 0.001$. SAA, Serum amyloid protein. 

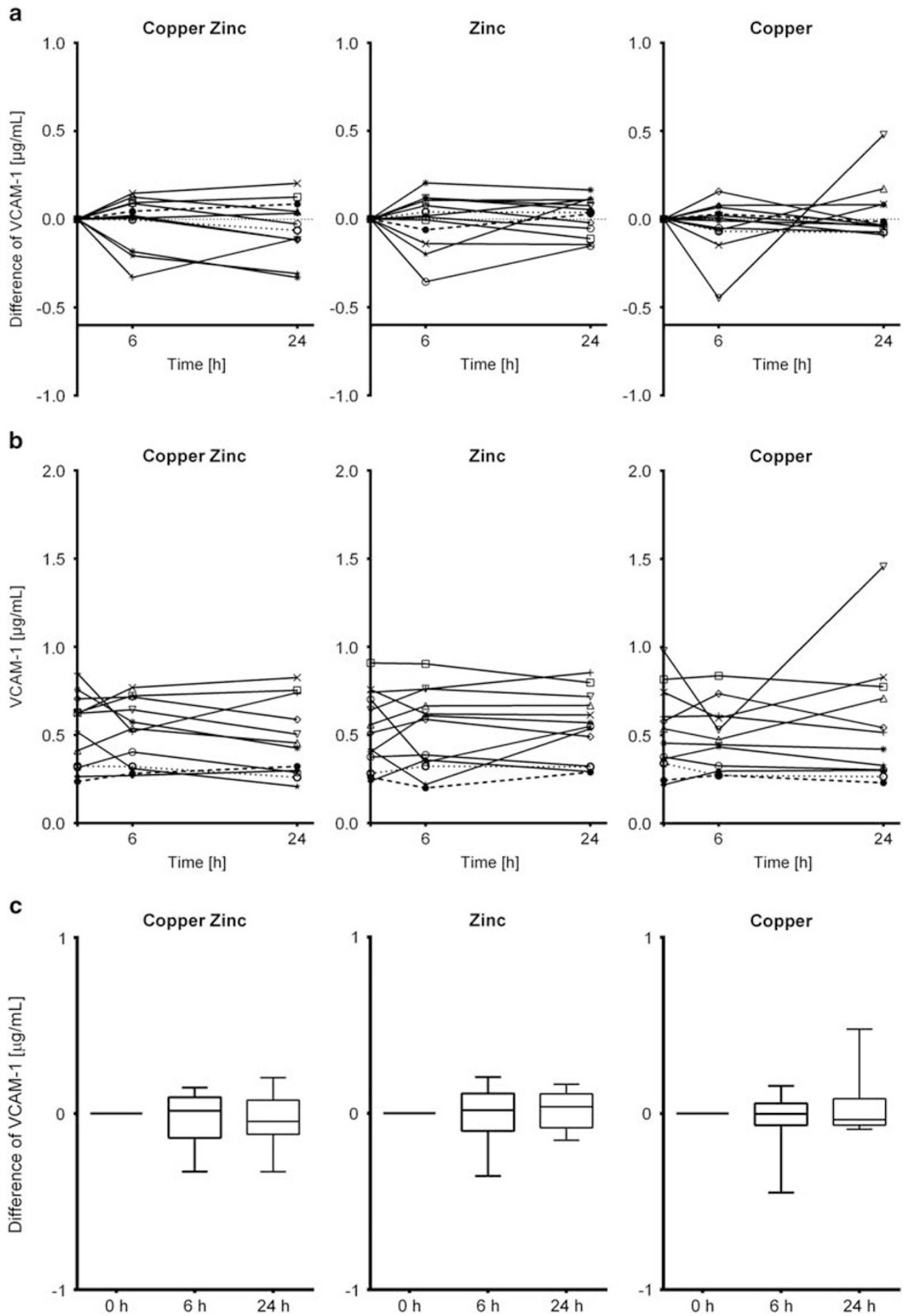

Figure 2. VCAM-1 concentrations in the blood for the three different exposure scenarios with welding fume containing copper and zinc together, zinc alone as well as copper alone. (a-c) represent alternative depictions of the results. (a) Time course of the difference of the VCAM-1 concentrations compared with the base value for each participant and exposure scenario. (b) Time course of the VCAM-1 concentrations for each participant and exposure scenario. (c) Box-and-Whisker Plot comparison of the differences of the VCAM-1 concentration compared with the base value at the time points. The hypothesis that the median of the difference of VCAM-1 at $6 \mathrm{~h}$, or $24 \mathrm{~h}$, after exposure versus before exposure is equal to zero was tested using the Wilcoxon signed rank test. A $P$-value of $\leq 0.05$ was judged significant. The levels of VCAM-1 remained largely unaffected, and hence no statistically significant differences were found. VCAM-1, vascular cell adhesion molecule- 1 .

In a previous paper we reported about the systemic CRP levels for the three described exposure scenarios. ${ }^{6}$ Therefore, we investigated to which extent the performances of the two acutephase proteins SAA and CRP were comparable, and whether the additional use of SAA besides CRP improves the detection of the acute-phase responses to zinc- and/or copper-containing welding fume exposures. We first tested for correlations between the systemic concentrations of SAA and CRP at $24 \mathrm{~h}$ after exposure. We 
a

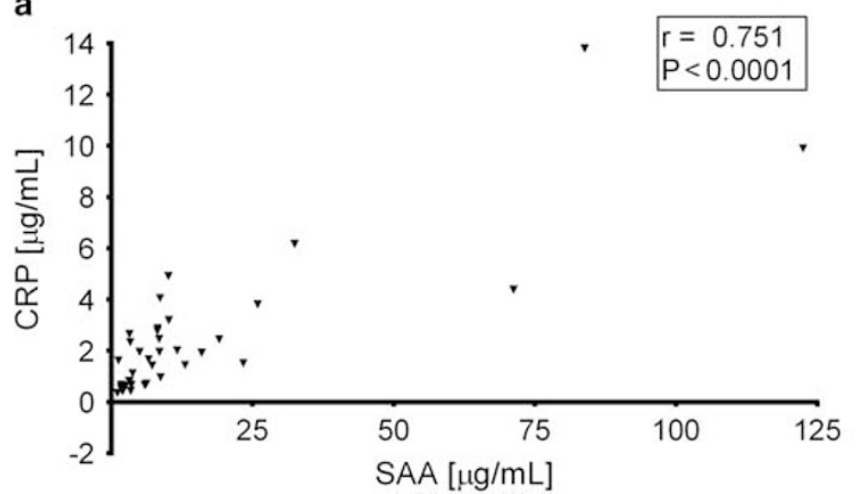

b

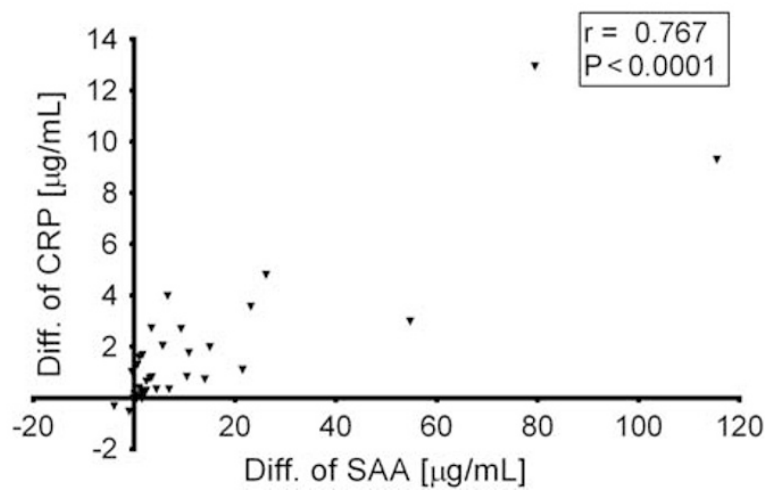

Figure 3. Correlations of the systemic CRP and SAA concentrations (a) and increases (b) $24 \mathrm{~h}$ after start of the $6 \mathrm{~h}$ exposure with the three different exposure scenarios with welding fume containing "copper and zinc" together, "zinc alone" as well as "copper alone". The correlation coefficient and the $P$-value were calculated using the Spearman rank test. Full CRP data were published in Markert et al.." Diff., Difference; CRP, C-reactive protein; SAA, Serum amyloid protein.

Table 1. Area under the ROC curve values for the biomarker discriminations of the three different welding fume exposures from baseline.

\begin{tabular}{lcc}
\hline Welding fume & SAA $(29 h$ vs $0 h)$ & CRP $(29 h$ vs $0 h)$ \\
\hline Copper & 0.833 & 0.795 \\
Zinc & 0.663 & 0.672 \\
Copper Zinc & 0.826 & 0.861 \\
\hline
\end{tabular}

found that the systemic concentration levels of these two acutephase proteins are correlated to each other $(r=0.751, P<0.0001)$ (Figure $3 a)$, suggesting that a more general systemic acute-phase response to the inhaled welding fumes was triggered in most individuals. Still, the performance of both biomarkers was not fully comparable: For some individuals, higher increases of SAA were accompanied by a relatively moderate increase of CRP (Figure $3 b$ ). And for other individuals, this relation was found to exist vice versa: Higher increases of CRP were accompanied by relatively moderate increases of SAA (Figure 3b). In order to further compare the performance of both biomarkers, we performed ROC curve analyses and calculated the corresponding AUC values. We compared the absolute SAA and CRP concentrations at $24 \mathrm{~h}$ post exposure with those values before exposure (Table 1). For the exposure with "only copper" welding fume, the AUC for SAA was with 0.83 slightly higher than the corresponding AUC for CRP (0.795). In contrast, for the exposure with "copper zinc" welding fume, the AUC for SAA (0.826) was slightly lower than the corresponding value for CRP (0.861). Overall, these ROC results confirm, that the performances of SAA and CRP after zinc- and/or copper-containing welding fumes are comparable for most but not all individuals. Owing to the lack of a parallel ambient air control exposure (which was not conducted, as in previous studies CRP levels remained unchanged after control exposure ${ }^{5,6,21}$ ), we could not perform an alternative ROC analysis considering the changes of SAA and CRP at $24 \mathrm{~h}$ (versus baseline) after welding fume exposure with the respective changes of SAA and CRP after ambient air exposure.

Of note, the values between the third quartile and the maximum of the Box-and-Whisker plots for the increases of SAA at $24 \mathrm{~h}$ after start of exposure show a wide distribution (Figure 1c), which shows that some individuals react with very distinct elevations of SAA. For some subjects and exposure types, SAA reached considerable values of up to $123 \mu \mathrm{l} / \mathrm{ml}$ at this time point. Of note, the highest values of systemic SAA for the three different exposure scenarios concerned the very same individual (Figures $1 \mathrm{a}$ and $\mathrm{b}$ ).

\section{DISCUSSION}

Our main finding is that the systemic acute-phase reactant SAA is substantially and significantly elevated 1 day after the start of a $6 \mathrm{~h}$ exposure with copper- and/or zinc-containing welding fumes. This shows that the previously described elevation of systemic $\mathrm{CRP}^{5-7}$ is not an isolated phenomenon, but that a more general systemic subclinical acute-phase response is occurring after inhalation of the described welding fumes. The performance of SAA was to a large extent similar to the one of CRP, and both markers were significantly correlated to each other. SAA showed a wider range of concentrations than did CRP, and its levels increased up to 19-fold after welding fume exposure.

In an occupationally oriented exposure study it is of interest whether the controlled exposures studied relate to a typical occupational exposure. The tested exposure conditions with zincand/or copper-containing welding fumes represent a worst-case scenario. First, the exposure doses tested are close to the workplace-related threshold value of $3 \mathrm{mg} / \mathrm{m}^{3}$. Second, it was assumed that no personal protection equipment was used. And third, exposures for six welding hours on 1 day were investigated. Furthermore, a cyclic exposure with the potential to reflect real workplace conditions was applied. In contrast to real workplace conditions, the welding fume exposures tested were investigated in a controlled fashion, and were not mixed with potential other workplace-related toxic exposures. For these reasons, the controlled exposures studies may provide valuable hints for typical occupational exposures. Another study reported that young smoking and non-smoking welders at an apprentice welding school showed significant CRP increases at $24 \mathrm{~h}$ after start of a welding fume exposure for $5.3 \mathrm{~h}$ exposure. ${ }^{22}$ A further study reported an increased inflammatory response, including elevations of CRP, after occupational air pollutants. ${ }^{23}$

This study confirms that copper- and zinc-welding particles are independent from each other potentially harmful for human health. The recognition of copper as a potential harmful component in welding fumes, also independent from zinc, deserves further consideration, particularly owing to the increasing role of copper in modern joining technology, especially in the automotive industry. In the year 2000, copper fume- and dust copperinduced systemic inflammation was judged to be a rare event on the basis of insufficient scientific literature about possible adverse health effects. ${ }^{24}$ However, recent insights including the current study show that this question is not completely answered. ${ }^{25}$ When comparing the biological effects of the "copper only" and the "zinc only" short-term exposure (with $0.4 \mathrm{mg} / \mathrm{m}^{3}$ copper, and $1.5 \mathrm{mg} / \mathrm{m}^{3}$ zinc, respectively), we observed in both cases significant increases 
of SAA. However, the effects of zinc tended to be less pronounced than the effects of copper - especially as the copper content of the welding fume was considerably lower than the zinc content. A similar observation was made for CRP previously. ${ }^{7}$ Furthermore, among 24 manufactured nanoparticles, which were compared for their toxicity in vitro in human alveolar epithelial and macrophage cell lines, copper- and zinc-based nanoparticles appeared to be the most toxic, especially for human macrophages. ${ }^{26}$ In this connection, the particle size seems to have an important role, for human epithelial cells, it was shown that nanoparticles of $\mathrm{CuO}$ were much more toxic compared with micrometer particles of $\mathrm{CuO}^{27}$

Although the median for the SAA increases after inhalation of zinc-containing welding fume is lower than the respective median after inhalation of "copper only" welding fume, the elevations of SAA are relatively high in some cases. Thereby, our study suggests that zinc as welding fume component may have to be carefully considered, at least for a subgroup of workers in the sense of an individual health surveillance. Zinc oxide contained in the particulate fraction of welding fumes is generally regarded as a constituent causing acute respiratory illness. ${ }^{1,2,28,29}$ Furthermore, zinc oxide nanoparticles have been implicated in lysosomal destabilization in a human macrophage cell line. ${ }^{30}$

SAA is regarded as a biomarker of COPD and inflammatory joint disease that is more sensitive than CRP. ${ }^{13,31}$ Accumulating evidence suggests that SAA is a biomarker and a mediator of atherosclerosis: Increased SAA levels have been identified as a predictor of coronary artery disease and cardiovascular outcome, and serve as an indicator for the extent of the disease. ${ }^{14}$ Furthermore, elevated systemic SAA levels are a hallmark of individuals who suffer from obesity and diabetes, ${ }^{32,33}$ and these inflammatory diseases are linked to an increased risk of developing atherosclerosis and heart disease. ${ }^{34,35}$ Moreover, in an animal experiment with apolipoprotein E-deficient mice, the overexpression of SAA directly accelerated the progression of atherosclerosis independent of all other risk factors. ${ }^{15}$ Strikingly, mice receiving only a single injection of SAA also had increased atherosclerosis compared with controls. ${ }^{16}$ These data suggest that even short-term inflammation with concomitant increase in SAA may increase the risk of developing cardiovascular disease. These observations are in line with epidemiological data suggesting that individuals with a history of intensive hospitalization or injury with a concomitant acute-phase response have increased subsequent mortality primarily from cardiovascular disease. ${ }^{36,37}$ In addition, when a cohort of elderly persons with ischemic heart disease were followed for 6 months and CRP levels were correlated with ambient air pollution (SAA was not assessed), CRP levels were statistically significantly associated with $\mathrm{PM}_{2.5}{ }^{38}$ CRP is a well-known risk factor for cardiovascular disease, independent from SAA. ${ }^{8,39,40}$ Whether CRP also has a causal relationship to cardiovascular diseases, is under debate. ${ }^{8,41,42}$ In contrast to CRP, SAA is more often discussed as causal factor for cardiovascular disease. ${ }^{15,16,43}$

Furthermore, SAA exhibits pro-inflammatory characteristics such as the attraction of phagocytes, the induction of proinflammatory cytokines and the delay of neutrophil apoptosis, ${ }^{11,12}$ which may contribute to the pathogenesis of atherosclerosis. SAA has been reported to act pro-atherogenic also by driving an increase in vascular biglycan content, predisposing the vessel wall to increased retention of atherogenic lipoproteins. ${ }^{16,44}$ SAA exerts many of its immunological activities by binding and activating cell-surface receptors, including Toll-like receptor (TLR)2 and TLR4, formyl peptide receptor-like 1 (FPRL1), class B scavenger receptor CD36 and the ATP receptor P2X7. ${ }^{12}$ The majority of published functional studies dealing with SAA have shown its pro-inflammatory activities using commercially available recombinant human (rh) SAA derived from Escherichia coli expression. Hence, possible lipopolysaccharide (LPS) contaminations of rhSAA could have a role, considering the lipid-binding propensity of SAA and the fact that the LPS receptor TLR4 is one of the reported SAA receptors. However, the cytokine-inducing activity of rSAA could be confirmed by rSAA-stimulated macrophages from the C57BL/ $10 \mathrm{ScN}$ mice, which lack functional TLR4. ${ }^{12}$

We did not find any significant changes of systemic soluble VCAM- 1 in any of the three exposure scenarios. Soluble VCAM- 1 is considered the most abundant of the circulating cell adhesion molecules (CAM) and is upregulated in a number of inflammatory conditions. Furthermore, VCAM-1 has been found to be a suitable biomarker for chronic exposure to biomass fuel smoke. ${ }^{45}$ However, consistent with our results, the expression of VCAM-1 did not obviously change in comparison with the control in in vitro zinc oxide nanoparticles-treated human umbilical vein endothelial cells. ${ }^{46}$ As many cells use several different CAMs to mediate cellcell adhesion, it might be helpful to investigate further CAM candidates in future studies. The fact that the biomarker soluble VCAM-1 did not show any relevant increases in our study shows that the induction of the acute-phase response via CRP and/or SAA after short-term inhalation of zinc- and/or copper-containing welding fumes is a specific reaction.

A weakness of the study is the small study group size and that no blood sampling occurred between $6 \mathrm{~h}$ and $24 \mathrm{~h}$ after exposure start. The lack of an ambient air exposure under identical controlled conditions is a further weakness of the study. Such a control exposure would help to confirm the specificity of the results. Previously performed welding studies included ambient air exposures, which yielded no significant changes of CRP. ${ }^{5,6,21}$ Also for another welding fume tested, an aluminum containing metal inert gas welding fumes, ${ }^{5}$ no changes of CRP were detected. ${ }^{5}$ Moreover, in the present study, significant changes of the acute-phase response were only found at $24 \mathrm{~h}$ compared with baseline at $0 \mathrm{~h}$, which excludes any chronobiological variations. For these reasons, the results of the present study suggest a specific moderate acute-phase response after zinc- and/or coppercontaining welding fumes.

Whether the acute-phase reactants could be used not only to determine potentially harmful effects for all involved study participants (a group) after controlled inhalation of zinc- and/or copper-containing welding fumes, but also as potential preventive personalized biomarkers for the early recognition of inflammatory effects of an individual, cannot be answered from this small pilot study. The usage of personalized biomarkers would be desirable, as they may serve as objective means to protect more sensitive individuals from over-exposure with certain welding fumes in the sense of an occupational health surveillance. The positive correlation between SAA and CRP, besides the fact that the highest values of systemic SAA concern the very same individual, may suggest that CRP and SAA might be biomarkers, which might also be helpful to evaluate the health effects of zinc- and/or copper-containing welding fumes for an individual worker, independent from the fact whether the remainder of welders working with similar fumes have healthiness problems or not. Therefore, future studies should address in larger cohorts, whether CRP and SAA are candidate biomarkers that might be very helpful also for the individual occupational medicine prevention for welders working with zinc- and/or copper-containing welding materials, to prevent potential harmful effects also on long-term cardiovascular health. These larger studies should also investigate individual variability in CRP and SAA responses and whether it is favorable to measure both biomarkers instead of only one of them, as it has been suggested for several infectious or inflammatory diseases. ${ }^{47-49}$ Moreover, further work is required to investigate whether the described inflammatory responses after exposure with zinc and copper fumes occur also at real work places. In addition, it will be important to investigate, whether long-term occupational exposure with zinc- and coppercontaining metal fumes among metal workers leads to a chronic elevation of the acute-phase response. Epidemiological, 
biomedical and clinical studies indicate that air pollution, for example, ambient particulate matter (PM), is strongly associated with increased cardiovascular diseases. ${ }^{50-52}$ Future research should elucidate whether and to which extent also the inhalation of welding fumes, including zinc- and copper-containing metal fumes, contribute to an increased risk for this type of disease. A large long-term epidemiological study with male metal workers showed an increased risk for cardiovascular diseases after longterm exposure to welding processed particles, also after adjustment for smoking. ${ }^{3}$

\section{CONCLUSIONS}

Zinc- as well as copper- containing welding fumes are able to induce increased values of SAA (this study) and $\mathrm{CRP}^{5-7} 1$ day after a short-term exposure. This moderate acute-phase response may vary to a certain extent for different individuals and may represent an increased health risk in the case of frequent exposure. Furthermore, CRP and SAA are both robust biomarkers that indicate an increased risk for cardiovascular risk, ${ }^{8,14}$ and both markers, particularly SAA, may functionally contribute to this type of disease. ${ }^{15,16}$ The consideration of these data may be important for the general and individual short- as well as long-term occupational health surveillance of workers working with these metal fumes, which become more common in modern joining technology.

\section{CONFLICT OF INTEREST}

The authors declare no conflict of interest.

\section{ACKNOWLEDGEMENTS}

This project was funded by the Institution for statutory accident insurance and prevention in the woodworking and metalworking industry (BGHM), Hannover, Germany, with an unrestricted grant to the University hospital RWTH Aachen.

\section{REFERENCES}

1 Antonini JM. Health effects of welding. Crit Rev Toxicol 2003; 33: 61-103.

2 Antonini JM, Lewis $A B$, Roberts JR, Whaley DA. Pulmonary effects of welding fumes: review of worker and experimental animal studies. Am J Ind Med 2003; 43: 350-360.

3 Ibfelt E, Bonde JP, Hansen J. Exposure to metal welding fume particles and risk for cardiovascular disease in Denmark: a prospective cohort study. Occup Environ Med 2010; 67: 772-777.

4 Pesch B, Weiss T, Kendzia B, Henry J, Lehnert M, Lotz A et al. Levels and predictors of airborne and internal exposure to manganese and iron among welders. $J$ Expos Sci Environ Epidemiol 2012; 22: 291-298.

5 Hartmann L, Bauer M, Bertram J, Gube M, Lenz K, Reisgen U et al. Assessment of the biological effects of welding fumes emitted from metal inert gas welding processes of aluminium and zinc-plated materials in humans. Int J Hygiene Environ Health 2014; 217: 160-168.

6 Brand P, Bauer M, Gube M, Lenz K, Reisgen U, Spiegel-Ciobanu VE et al. Relationship between welding fume concentration and systemic inflammation after controlled exposure of human subjects with welding fumes from metal inert gas brazing of zinc-coated materials. J Occup Environ Med 2014; 56: 1-5.

7 Markert A, Baumann R, Gerhards B, Gube M, Kossack V, Kraus T et al. Single and combined exposure to zinc- and copper-containing welding fumes lead to asymptomatic systemic inflammation. J Occup Environ Med 2016; 58: 127-132.

8 Kaptoge S, Di Angelantonio E, Pennells L, Wood AM, White IR, Gao P et al. C-reactive protein, fibrinogen, and cardiovascular disease prediction. $N$ Engl J Med 2012; 367: 1310-1320.

9 Upragarin N, Landman WJ, Gaastra W, Gruys E. Extrahepatic production of acute phase serum amyloid A. Histol Histopathol 2005; 20: 1295-1307.

10 Manley PN, Ancsin JB, Kisilevsky R. Rapid recycling of cholesterol: the joint biologic role of C-reactive protein and serum amyloid A. Med Hypotheses 2006; 66: 784-792.

11 Christenson K, Bjorkman L, Tangemo C, Bylund J. Serum amyloid A inhibits apoptosis of human neutrophils via a P2X7-sensitive pathway independent of formyl peptide receptor-like 1. J Leukoc Biol 2008; 83: 139-148.
12 Ye RD, Sun L. Emerging functions of serum amyloid A in inflammation. J Leukoc Biol 2015; 98: 923-929.

13 Bozinovski S, Hutchinson A, Thompson M, Macgregor L, Black J, Giannakis E et al. Serum amyloid $a$ is a biomarker of acute exacerbations of chronic obstructive pulmonary disease. Am J Respir Crit Care Med 2008; 177: 269-278.

14 Johnson BD, Kip KE, Marroquin OC, Ridker PM, Kelsey SF, Shaw L et al. Serum amyloid $\mathrm{A}$ as a predictor of coronary artery disease and cardiovascular outcome in women: the National Heart, Lung, and Blood Institute-Sponsored Women's Ischemia Syndrome Evaluation (WISE). Circulation 2004; 109: 726-732.

15 Dong Z, Wu T, Qin W, An C, Wang Z, Zhang M et al. Serum amyloid A directly accelerates the progression of atherosclerosis in apolipoprotein E-deficient mice. Mol Med 2011; 17: 1357-1364.

16 Thompson JC, Jayne C, Thompson J, Wilson PG, Yoder MH, Webb N et al. A brief elevation of serum amyloid $\mathrm{A}$ is sufficient to increase atherosclerosis. $J$ Lipid Res 2015; 56: 286-293.

17 Ley K, Huo Y. VCAM-1 is critical in atherosclerosis. J Clin Invest 2001; 107: 1209-1210.

18 Byrne GJ, Ghellal A, Iddon J, Blann AD, Venizelos V, Kumar S et al. Serum soluble vascular cell adhesion molecule-1: role as a surrogate marker of angiogenesis. JNatl Cancer Inst 2000; 92: 1329-1336.

19 Brand P, Havlicek P, Steiners M, Holzinger K, Reisgen U, Kraus T et al. Exposure of healthy subjects with emissions from a gas metal arc welding process: part 1--exposure technique and external exposure. Int Archs Occup Environ Health 2013; 86: 25-30.

20 Yael Rosenberg-Hasson Y, Hansmann L, Liedtke M, Herschmann I, Maecker HT. Effects of serum and plasma matrices on multiplex immunoassays. Immunol Res. 2014; 58: 224-233.

21 Dewald E, Gube M, Baumann R, Bertram J, Kossack V, Lenz K et al. Assessment of the biological effects of welding fumes emitted from metal active gas and manual metal arc welding in humans. J Occup Environ Med 2015; 57: 845-850.

$22 \mathrm{Kim} \mathrm{JY,} \mathrm{Chen} \mathrm{JC,} \mathrm{Boyce} \mathrm{PD,} \mathrm{Christiani} \mathrm{DC.} \mathrm{Exposure} \mathrm{to} \mathrm{welding} \mathrm{fumes} \mathrm{is} \mathrm{associated}$ with acute systemic inflammatory responses. Occup Environ Med 2005; 62: 157-163.

23 Ohlson CG, Berg P, Bryngelsson IL, Elihn K, Ngo Y, Westberg H et al. Inflammatory markers and exposure to occupational air pollutants. Inhal Toxicol 2010; 22: 1083-1090.

24 Borak J, Cohen H, Hethmon TA. Copper exposure and metal fume fever: lack of evidence for a causal relationship. AlHAJ 2000; 61: 832-836.

25 Saha A, Karnik A, Sathawara N, Kulkarni P, Singh V. Ceruloplasmin as a marker of occupational copper exposure. J Expos Sci Environ Epidemiol 2008; 18: 332-337.

26 Lanone S, Rogerieux F, Geys J, Dupont A, Maillot-Marechal E, Boczkowski J et al. Comparative toxicity of 24 manufactured nanoparticles in human alveolar epithelial and macrophage cell lines. Particle Fibre Toxicol 2009; 6: 14.

27 Karlsson HL, Cronholm P, Gustafsson J, Moller L. Copper oxide nanoparticles are highly toxic: a comparison between metal oxide nanoparticles and carbon nanotubes. Chem Res Toxicol 2008; 21: 1726-1732.

28 Blanc PD, Boushey HA, Wong H, Wintermeyer SF, Bernstein MS. Cytokines in metal fume fever. Am Rev Respir Dis 1993; 147: 134-138.

29 Kuschner WG, D'Alessandro A, Wong H, Blanc PD. Early pulmonary cytokine responses to zinc oxide fume inhalation. Environ Res 1997; 75: 7-11.

30 Cho WS, Duffin R, Howie SE, Scotton CJ, Wallace WA, Macnee W et al. Progressive severe lung injury by zinc oxide nanoparticles; the role of $\mathrm{Zn} 2+$ dissolution inside lysosomes. Particle Fibre Toxicol 2011; 8: 27.

31 Cunnane G, Grehan S, Geoghegan S, McCormack C, Shields D, Whitehead AS et al. Serum amyloid $A$ in the assessment of early inflammatory arthritis. J Rheumatol 2000; 27: 58-63.

32 Leinonen E, Hurt-Camejo E, Wiklund O, Hulten LM, Hiukka A, Taskinen MR. Insulin resistance and adiposity correlate with acute-phase reaction and soluble cell adhesion molecules in type 2 diabetes. Atherosclerosis 2003; 166: 387-394.

33 O'Brien KD, Brehm BJ, Seeley RJ, Bean J, Wener MH, Daniels S et al. Diet-induced weight loss is associated with decreases in plasma serum amyloid a and C-reactive protein independent of dietary macronutrient composition in obese subjects. J Clin Endocrinol Metab 2005; 90: 2244-2249.

34 Kannel WB, McGee DL. Diabetes and glucose tolerance as risk factors for cardiovascular disease: the Framingham study. Diabetes Care 1979; 2: 120-126.

35 Rabkin SW, Mathewson FA, Hsu PH. Relation of body weight to development of ischemic heart disease in a cohort of young North American men after a 26 year observation period: the Manitoba Study. Am J Cardiol 1977; 39: 452-458.

36 Coca SG, Yusuf B, Shlipak MG, Garg AX, Parikh CR. Long-term risk of mortality and other adverse outcomes after acute kidney injury: a systematic review and meta-analysis. Am J Kidney Dis 2009; 53: 961-973.

37 Quartin AA, Schein RM, Kett DH, Peduzzi PN. Magnitude and duration of the effect of sepsis on survival. Department of Veterans Affairs Systemic Sepsis Cooperative Studies Group. JAMA 1997; 277: 1058-1063. 
38 Huttunen K, Siponen T, Salonen I, Yli-Tuomi T, Aurela M, Dufva H et al. Low-level exposure to ambient particulate matter is associated with systemic inflammation in ischemic heart disease patients. Environ Res 2012; 116: 44-51.

39 Cesari M, Penninx BW, Newman AB, Kritchevsky SB, Nicklas BJ, Sutton-Tyrrell K et al. Inflammatory markers and cardiovascular disease (The Health, Aging and Body Composition [Health ABC] Study). Am J Cardiol 2003; 92: 522-528.

40 Ridker PM, Hennekens $\mathrm{CH}$, Buring JE, Rifai N. C-reactive protein and other markers of inflammation in the prediction of cardiovascular disease in women. $N$ Engl $J$ Med 2000; 342: 836-843.

41 Elliott P, Chambers JC, Zhang W, Clarke R, Hopewell JC, Peden JF et al. Genetic Loci associated with $\mathrm{C}$-reactive protein levels and risk of coronary heart disease. JAMA 2009; 302: 37-48.

42 Pepys MB, Hirschfield GM, Tennent GA, Gallimore JR, Kahan MC, Bellotti V et al. Targeting $\mathrm{C}$-reactive protein for the treatment of cardiovascular disease. Nature 2006; 440: 1217-1221.

43 Saber AT, Jacobsen NR, Jackson P, Poulsen SS, Kyjovska ZO, Halappanavar S et al. Particle-induced pulmonary acute phase response may be the causal link between particle inhalation and cardiovascular disease. Wiley Interdiscipl Rev Nanomed Nanobiotechnol 2014; 6: 517-531.

44 Wilson PG, Thompson JC, Webb NR, de Beer FC, King VL, Tannock LR. Serum amyloid $\mathrm{A}$, but not $\mathrm{C}$-reactive protein, stimulates vascular proteoglycan synthesis in a pro-atherogenic manner. Am J Pathol 2008; 173: 1902-1910.

45 Caravedo MA, Herrera PM, Mongilardi N, de Ferrari A, Davila-Roman VG Gilman RH et al. Chronic exposure to biomass fuel smoke and markers of endothelial inflammation. Indoor Air 2015; 26: 768-775.

$46 \mathrm{Li} \mathrm{CH}$, Liao PL, Shyu MK, Liu CW, Kao CC, Huang SH et al. Zinc oxide nanoparticlesinduced intercellular adhesion molecule 1 expression requires Rac1/Cdc42, mixed lineage kinase 3 , and c-Jun $\mathrm{N}$-terminal kinase activation in endothelial cells. Toxicol Sci 2012; 126: 162-172.
47 Jovanovic DB. Clinical importance of determination of serum amyloid A. Srp Arh Celok Lek 2004; 132: 267-271.

48 Lannergard A, Larsson A, Kragsbjerg P, Friman G. Correlations between serum amyloid A protein and C-reactive protein in infectious diseases. Scand J Clin Lab Invest 2003; 63: 267-272.

49 Smith JW, Colombo JL, McDonald TL. Comparison of serum amyloid A and C-reactive protein as indicators of lung inflammation in corticosteroid treated and non-corticosteroid treated cystic fibrosis patients. J Clin Lab Anal 1992; 6: 219-224.

50 Brook RD, Rajagopalan S, Pope CA 3rd, Brook JR, Bhatnagar A, Diez-Roux AV et al. Particulate matter air pollution and cardiovascular disease: An update to the scientific statement from the American Heart Association. Circulation 2010; 121: 2331-2378.

51 Du Y, Xu X, Chu M, Guo Y, Wang J. Air particulate matter and cardiovascular disease: the epidemiological, biomedical and clinical evidence. J Thorac Dis 2016; 8: E8-e19.

52 Miller KA, Siscovick DS, Sheppard L, Shepherd K, Sullivan JH, Anderson GL et al. Long-term exposure to air pollution and incidence of cardiovascular events in women. N Eng J Med 2007; 356: 447-458.

(c) (i) $(-)$ This work is licensed under a Creative Commons AttributionCy NC ND NonCommercial-NoDerivs 4.0 International License. The images or other third party material in this article are included in the article's Creative Commons license, unless indicated otherwise in the credit line; if the material is not included under the Creative Commons license, users will need to obtain permission from the license holder to reproduce the material. To view a copy of this license, visit http:// creativecommons.org/licenses/by-nc-nd/4.0/

(c) The Author(s) 2018 